\title{
Antidotal Efficacies of the Cyanide Antidote Candidate Dimethyl Trisulfide Alone and in Combination with Cobinamide Derivatives
}

Ilona Petrikovics, Lóránd Kiss, Ching-en Chou, Afshin Ebrahimpour, Kristóf Kovács, Márton Kiss, Brian Logue, Adriano Chan, Ananda B.W. Manage, Marianna Budai, Gerry R. Boss \& Gary A. Rockwood

To cite this article: Ilona Petrikovics, Lóránd Kiss, Ching-en Chou, Afshin Ebrahimpour, Kristóf Kovács, Márton Kiss, Brian Logue, Adriano Chan, Ananda B.W. Manage, Marianna Budai, Gerry R. Boss \& Gary A. Rockwood (2019): Antidotal Efficacies of the Cyanide Antidote Candidate Dimethyl Trisulfide Alone and in Combination with Cobinamide Derivatives, Toxicology Mechanisms and Methods, DOI: $10.1080 / 15376516.2019 .1585504$

To link to this article: https://doi.org/10.1080/15376516.2019.1585504

Accepted author version posted online: 01

Mar 2019.

Submit your article to this journal $\pi$

Џ Article views: 3

View Crossmark data $\subset$ 


\section{Antidotal Efficacies of the Cyanide Antidote Candidate Dimethyl Trisulfide Alone and in Combination with Cobinamide Derivatives}

Ilona Petrikovics ${ }^{1}$, Lóránd Kiss ${ }^{1}$, Ching-en Chou ${ }^{1}$, Afshin Ebrahimpour ${ }^{1}$, Kristóf

Kovács ${ }^{1}$, Márton Kiss ${ }^{1}$, Brian Logue ${ }^{2}$, Adriano Chan $^{3}$, Ananda B.W. Manage ${ }^{4}$,Marianna

Budai $^{1}$, Gerry R. Boss ${ }^{3}$, Gary A. Rockwood ${ }^{5}$

${ }^{1}$ Department of Chemistry, Sam Houston State University, Huntsville, Texas, 77341, USA

${ }^{2}$ Department of Chemistry and Biochemistry, South Dakota State University, Brookings, SD 57007, USA

${ }^{3}$ Department of Medicine, University of California, San Diego, La Jolla, CA, 92093-0652, USA

${ }^{4}$ Department of Mathematics and Statistics, Sam Houston State University, Huntsville, Texas, 77341, USA

${ }^{5}$ US Army Medical Research Institute of Chemical Defense, APG, MD, 21010, USA

Contact information:

Dr. Ilona Petrikovics, e-mail: ixp004@shsu.edu

Department of Chemistry, Sam Houston State University, 1003 Bowers Blvd, Huntsville, Texas, 77341

936-294-4389 


\section{Abstract}

Formulation optimization and antidotal combination therapy are the two important tools to enhance the antidotal protection of the cyanide $(\mathrm{CN})$ antidote dimethyl trisulfide (DMTS). The focus of this study is to demonstrate how the formulation with polysorbate 80 (Poly80), an excipient used in pharmaceutical technology, and the combinations with other $\mathrm{CN}$ antidotes having different mechanisms of action enhance the antidotal efficacy of the unformulated (neat) DMTS. The $\mathrm{LD}_{50}$ for $\mathrm{CN}$ was determined by the statistical Dixon up-and-down method on mice. Antidotal efficacy was expressed as antidotal potency ratio (APR). CN was injected subcutaneously one minute prior to the antidotes' injection intramuscularly. The APR values of 1.17 (dose: $25 \mathrm{mg} / \mathrm{kg}$ bodyweight) and 1.45 (dose: $50 \mathrm{mg} / \mathrm{kg}$ bodyweight) of the neat DMTS were significantly enhanced by the Poly80 formulation at both investigated doses to 2.03 and 2.33 , respectively. The combination partners for the Poly80 formulated DMTS (DMTS-Poly80; 25 and $50 \mathrm{mg} / \mathrm{kg}$ bodyweight) were 4-nitrocobinamide (4NCbi) (20 mg/kg bodyweight) and aquohydroxocobinamide (AHCbi; 50, 100 and $250 \mathrm{mg} / \mathrm{kg}$ bodyweight). When DMTS-Poly80 (25 and $50 \mathrm{mg} / \mathrm{kg}$ bodyweight; APR=2.03 and 2.33 respectively) was combined with $4 \mathrm{NCbi}(20 \mathrm{mg} / \mathrm{kg}$ bodyweight; APR=1.35), significant increase in the APR values were noted at both DMTS doses (APR=2.38 and 3.12 respectively). AHCbi enhanced the APR of DMTS-Poly80 (100 mg/kg bodyweight; APR=3.29) significantly only at the dose of $250 \mathrm{mg} / \mathrm{kg}$ bodyweight (APR=5.86). These studies provided evidence for the importance of the formulation with Poly80 and the combinations with cobinamide derivatives with different mechanisms of action for DMTS as a CN antidote candidate. 
Keywords: Combination therapy, Intramuscular antidote injection, Subcutaneous Cyanide exposure, Cobinamide, Dimethyl trisulfide

\section{Abbreviations}

$\begin{array}{ll}\text { APR } & \text { Antidotal potency ratio } \\ \text { CN } & \left.\text { Cyanide (as } \mathrm{CN}^{-} \text {and/or } \mathrm{HCN}\right) \\ \text { DMTS } & \text { Dimethyl trisulfide } \\ \text { MetHb } & \text { Methemoglobin } \\ \text { Poly80 } & \text { Polysorbate } 80 \\ \text { DMTS-Poly80 } & \text { Polysorbate } 80 \text { formulated DMTS } \\ \text { Cbi } & \text { Cobinamide } \\ \text { AHCbi } & \text { Aquohydroxocobinamide } \\ 4 \mathrm{NCbi} & \text { 4-Nitrocobinamide }\left[\left(\mathrm{Cbi}\left(\mathrm{NO}_{2}\right)_{2}+2 \text { eqv. } \mathrm{NO}_{2}\right] \text { or }\right. \\ & \begin{array}{l}{\left[\left(\text { Cbi }\left(\mathrm{NO}_{2}\right){ }_{4}\right)\right]} \\ \text { DNCbi }\end{array} \\ \text { CI } & \text { Dinitrocobinamide }\left[\mathrm{Cbi}\left(\mathrm{NO}_{2}\right)_{2}\right] \\ \text { SD } & \text { 95\% Confidence interval } \\ \text { SEM } & \text { Standard deviation } \\ \text { IM } & \text { Standard error of mean } \\ \text { Intramuscular }\end{array}$




\section{Introduction}

Cyanide $(\mathrm{CN})$, representing both $\mathrm{CN}^{-}$and $\mathrm{HCN}$ inclusively, inhibits the Cytochrome c Oxidase, the terminal oxidase of the mitochondrial electron transport chain, thereby suppressing cellular oxygen utilization and aerobic ATP production (Vogel et al., 1981; Way et al., 1988). The heart and the brain are the most susceptible organs to CN poisoning due to their high ATP demand. The two current FDA-approved CN therapies in the United States are Cyanokitß (Borron et al., 2006; Zakharov et al., 2015) and Nithiodote $^{T M}$ (Scottsdale, 2011). Cyanokit $\AA$ contains hydroxocobalamin, which acts as a $\mathrm{CN}$ scavenger. Nithiodote ${ }^{\mathrm{TM}}$ is a combination of sodium thiosulfate (acting as a sulfur donor to convert $\mathrm{CN}$ to the less toxic thiocyanate) and sodium nitrite (primarily acting as a methemoglobin (MetHb) former to scavenge $\mathrm{CN}$ ). Recent research revealed its other role of nitric oxide formation (Kanai et al., 2001). Both $\mathrm{CN}$ therapies have undesirable side effects, require large injection volumes during intravenous administration and are unsuitable for a mass casualty scenario (Marraffa et al., 2012). Furthermore, thiosulfate is dependent on the endogenous mitochondrial Rhodanese and has a limited cell penetrating capability and moderate chemical reactivity with $\mathrm{CN}$ to form thiocyanate (Rockwood et al., 2016; Schulz, 1984; Way et al., 1988). Additionally, overdosing nitrite can cause methemoglobinemia (Schulz, 1984; Way et al., 1988). These problems led to a search for improved countermeasures that would also guarantee rapid and easy administration, such as intramuscular (IM) injection.

One of the recent results of research efforts was the discovery of dimethyl trisulfide (DMTS) as the "Advanced Sulfur Donor" (Rockwood et al., 2016). DMTS is present in 
many natural sources, such as cabbage (Brassica oleracea var. capitate), broccoli (Brassica oleracea var. italic) cauliflower (Brassica oleracea var. botrytis), but it is present in the highest amounts in garlic (Allium sativum); each garlic bulb has 15-19 $\mu$ g DMTS (Block, 1985). Studies have shown that DMTS has significantly higher in vitro sulfur donor reactivity and in vivo antidotal efficacy than the present therapy, thiosulfate (DeLeon et al., 2018; Kiss et al., 2017; Rockwood et al., 2016). When formulations were investigated, the goal was to find a formulation that provides fast absorption with high $\mathrm{c}_{\max }$ and good antidotal protection after $\mathrm{IM}$ administration. Early attempts with formulations led to the lipid based micellar encapsulation of DMTS with 1,2-distearoyl-sn-glycero-3-phosphoethanolamine $\mathrm{N}$-[methoxy-(polyethylene glycol)2000] (PEG 2000 -DSPE) that provided remarkable antidotal protection at relatively low dose; however, its limited stability did not support further studies (Kovacs et al., 2016b). Further attention was focused on the DMTS formulation with the FDA-approved surfactant, polysorbate 80 (Poly80) (Kovacs et al., 2016a). The $15 \%$ Poly80 formulation provided the advantages of good absorption kinetics (Kiss et al., 2017), and high antidotal efficacy (Kovacs et al., 2016a). Pharmacokinetic studies demonstrated that the Poly80-formulated DMTS was rapidly absorbed (within 5-15 min) after IM administration (Kiss et al., 2017) and that the intravascular residence time was reasonable (elimination half-life $=36 \mathrm{~min})($ De Silva et al., 2016).

The shortcoming of the Poly80-formulated DMTS, namely the large injection volume extrapolated for humans -due to the limited solubility of DMTS in Poly80 $(75 \mathrm{mg} / \mathrm{ml})-$, initiated further efforts to develop new, optimized formulations, and/or combinations with other $\mathrm{CN}$ countermeasures having different mechanisms of action. The combination 
approach is also advantageous as it reduces the side effects (toxic effects) of each component.

Cobinamide is a cobalamin derivative, which has the advantage of allowing two CNs to bind to the cobalt ion of the Corrine ring (Lee et al., 2016). Cobinamide is $3-10$ times more potent than hydroxocobalamin in mouse, rabbit, and swine models (Chan et al., 2015; Chan et al., 2018; Cronican et al., 2018). It is reported that nitrocobinamide derivatives are very stable and are absorbed well after IM injection (Chan et al., 2015). This study reports the antidotal effects of the neat DMTS in comparison with the Poly80formulated DMTS (DMTS-Poly80) at the doses of $25 \mathrm{mg} / \mathrm{kg}$ bodyweight and $50 \mathrm{mg} / \mathrm{kg}$ bodyweight. To surpass the shortcomings of the DMTS-Poly80 alone, namely the required high injection volume due to the limited DMTS solubility, combination studies with two Cbi derivatives (4-nitrocobinamide, 4NCbi and aquohydroxocobinamide, AHCbi) were explored. The structures of these $\mathrm{Cbi}$ derivatives and the nomenclature of the 4NCbi were explained in earlier publications (Chan et al., 2015; Lee et al., 2016). Briefly, the $4 \mathrm{NCbi}$ is a combination itself. It consists of 1 eqv. Dinitrocobinamide (DNCbi) with two nitro groups attached to the cobalt ion in the Corrine ring, plus 2 eqv. of nitrite. To simplify the nomenclature we call this combination $4 \mathrm{NCbi}$. The combination of DMTS with Cbi derivatives represents one of the efforts to reduce the DMTS injection volume and dose while still achieving good antidotal protection. Formulation optimization, the other component of this effort, is part of the ongoing studies and will be published later. 


\section{Materials and Methods}

\section{Chemicals and Supplies for Animal Studies}

All chemicals were of the highest purity commercially available. DMTS $\left(\mathrm{C}_{2} \mathrm{H}_{6} \mathrm{~S}_{3}, \mathrm{CAS}\right.$ : 3658-80-8; $\geq 96 \%$ ), and Potassium cyanide (KCN, CAS:151-50-8; $\geq 98 \%$ ) were purchased from Sigma Aldrich (St. Louis, MO, USA). Poly80 (Polysorbate 80, $\mathrm{C}_{32} \mathrm{H}_{60} \mathrm{O}_{10}$, CAS: $9005-65-6, \geq 95 \%$ ) was purchased from Alfa Aesar (Haverhill, MA, USA). Dinitrocobinamide and aquohydroxocobinamide, (cobalt(3+);3$[(1 \sim\{R\}, 2 \sim\{S\}, 3 \sim\{S\}, 5 \sim\{Z\}, 7 \sim\{S\}, 8 \sim\{S\}, 10 \sim\{Z\}, 13 \sim\{S\}, 15 \sim\{Z\}, 17 \sim\{R\}, 18 \sim\{R\}, 19 \sim\{R\})-$ 2,7,18-tris(2-amino-2-oxoethyl)-3,13-bis(3-amino-3-oxopropyl)-17-[3-[[(2 \{R\})-2hydroxypropyl]amino]-3-oxopropyl]-1,2,5,7,12,12,15,17-octamethyl-8,13,18,19tetrahydro-3 $\{\mathrm{H}\}$-corrin-24-id-8-yl]propanamide, $\mathrm{C}_{48} \mathrm{H}_{72} \mathrm{CoN}_{11} \mathrm{O}_{8}{ }^{+2}, \mathrm{CAS}: 13497-85-$ 3) were prepared at UCLA (Broderick et al., 2005), and the purity of both was >95\% by HPLC from hydroxo-cobalamin (OH-Cbi, Sigma Chemical Co"). Hamilton Luer-lock syringes (VWR International, Suwanee, GA, USA) with volumes of 50, 100 and $250 \mu \mathrm{L}$ were used for IM (27G, $1 / 2$ inch needles) and subcutaneous injections (25G, 1 inch needles) in the animal studies.

\section{Animals}

Animal studies were conducted using healthy male CD-1 mice (18-20 g; Charles River Breeding Laboratories, Inc., Wilmington, Massachusetts and SHSU Animal Facility, Huntsville, Texas). Animal procedures were conducted in accordance with the guidelines by The Guide for the Care and Use of Laboratory Animals (National Academic Press, 2010), accredited by AAALAC (American Association for the 
Assessment and Accreditation of Laboratory Animal Care, International). The mice were fed with Zeigler Rodent RQ 18-6 diet (Zeigler Bros. Inc., Gardners, PA, USA) and water ad libitum, and were housed at $21^{\circ} \mathrm{C}$ in light-controlled rooms (12 h light/dark, fullspectrum lighting cycle with no twilight). At the termination of the experiments, animals were euthanized in accordance with the AVMA Guidelines for the Euthanasia of Animals: 2013 Edition (AVMA Guidelines). At Sam Houston State University, the Institutional Animal Care and Use Committee (IACUC) permission number is 15-09-141015.

\section{Solutions and Formulations}

\section{KCN Solutions-}

$20 \mathrm{mg} / \mathrm{ml} \mathrm{KCN}$ was created by adding $500 \mathrm{mg} \mathrm{KCN}$ and D.I water in a $25 \mathrm{ml}$ volumetric flask, and the solution was vortexed until the obvious crystals were dissolved. KCN ( $7.5 \mathrm{mg} / \mathrm{ml}$ ) was prepared by adding $8.33 \mathrm{ml}$ of $\mathrm{D} . \mathrm{I}$ water to $5 \mathrm{ml}$ of the $20 \mathrm{mg} / \mathrm{ml} \mathrm{KCN}$ solution, and was vortexed for $5 \mathrm{~min}$. $\mathrm{KCN}(5 \mathrm{mg} / \mathrm{ml}$ ) was made by adding $15 \mathrm{ml}$ of $\mathrm{D.I}$ water to $5 \mathrm{ml}$ of the $20 \mathrm{mg} / \mathrm{ml} \mathrm{KCN}$ solution, and was vortexed for $5 \mathrm{~min}$. KCN (2.5 $\mathrm{mg} / \mathrm{ml}$ ) was created by adding $21 \mathrm{ml}$ of D.I. water to $3 \mathrm{ml}$ of the $20 \mathrm{mg} / \mathrm{ml} \mathrm{KCN}$ solution, and was vortexed for $5 \mathrm{~min}$.

\section{5\% Poly80-formulated DMTS-}

This formulation was prepared as previously described (Kovacs et al., 2016a). Briefly, First the $15 \%(\mathrm{w} / \mathrm{w})$ Poly80 was prepared by dissolving $7.50 \mathrm{~g}$ Poly80 in $42.5 \mathrm{~g}$ of $\mathrm{D.I}$ water. It was vortexed for $5 \mathrm{~min}$, then auto-vortexed for 30 minutes. The solution was kept in the refrigerator overnight before use. To prepare $25 \mathrm{ml}$ of $50 \mathrm{mg} / \mathrm{ml}$ DMTS in 
$15 \%(w / w)$ Poly80 solution, $1.25 \mathrm{~g}$ DMTS was added to the $15 \%(w / w)$ Poly80 solution in a $25 \mathrm{ml}$ volumetric flask, and hand-vortexed for $5 \mathrm{~min}$. The solution was then vortexed for 30 min by an auto-vortexer (Heidolph Multi Reax) and was placed into glass vials for storage and crimped to be tightly sealed.

\section{Solutions for the DMTS and Cbi combination studies}

4NCbi injection solution [40mg/ml]. $13.92 \mathrm{mg} \mathrm{NaNO}$ was dissolved in $3 \mathrm{ml}$ of $15 \%$ Poly80 solution, then $71.792 \mathrm{mg}$ DNCbi was added, and the solution was vortexed for 5 min. $\quad$ AHCbi in water $[125 \mathrm{mg} / \mathrm{m}]]$ : was prepared for the AHCbi administration by dissolving AHCbi in water.

\section{In vivo Experiments}

Male CD-1 mice (18-20g) received the antidote solutions IM one minute after the KCN solution subcutaneously. The $\mathrm{LD}_{50}$ and $95 \%$ confidence interval values were determined by the simulated up-and-down method (Dixon, 1965; Dixon \& Massey, 1983; Bruce, 1985). USAMRICD provided a Microsoft Office Excel sheet that utilizes the equations from these methods to calculate the dose of $\mathrm{CN}$ to apply for each stage.

General Method for Antidotal Efficacy Studies: In the therapeutic antidotal efficacy experiments, CN was injected subcutaneously one minute prior to the antidotes injection intramuscularly, and the injection volume was calculated based on the dose, the animal weight, and the stock solution concentrations according to the following formula: Injection volume $(\mu \mathrm{l})=$ animal weight $(\mathrm{g}) \mathrm{X}$ dose $(\mathrm{mg} / \mathrm{kg}$ bodyweight $) /$ stock concentration $(\mathrm{mg} / \mathrm{ml})$. Each study, regardless of the number of treatment groups, contained a control group with KCN injection only, without antidote. After the injection of 
$\mathrm{KCN}$ and the antidote(s), the animals were kept in observation cages for two hours to monitor survival. Surviving animals were further observed for 24 hours, but based on our experience, if the animal is going to die, it does so within 2 hours post-KCN injection. Animals were declared dead if the following criteria were met: breathing stopped and no heart beat was detected (followed by the flipping from supine position to a prone position in most cases). The starting dose of $\mathrm{KCN}$ for the control was $10 \mathrm{mg} / \mathrm{kg}$ bodyweight. The starting KCN doses for the different test groups were chosen based on pilot experiments. If the antidote was expected to provide good protection, the starting dose of KCN for the group was higher (e.g. $30-40 \mathrm{mg} / \mathrm{kg}$ bodyweight). The dose of the test antidote solution was constant for each test group, and the injection volume was calculated based on the above formula what includes the weight of the animal, the dose, and the concentration of the test solution. The formulation concentration for the antidotes were: DMTS=50 mg/ml in Poly80; $4 \mathrm{NCbi}=40 \mathrm{mg} / \mathrm{ml}$ in Poly80; AHCbi=125 $\mathrm{mg} / \mathrm{ml}$ in water. The injection sites: DMTS alone was injected IM into the upper part (thigh) of one of the back legs; combinations of antidotes (DMTS and 4NCbi or AHCbi) were injected into the thigh of the two separate back legs, and the $\mathrm{CN}$ solution was injected subcutaneously (under the skin at the back part of the neck). The KCN dose for each stage varied within the group depending on instructions given by the software. To keep the KCN injection volume within the range of 80-120 $\mu \mathrm{l}$, the concentration of $\mathrm{KCN}$ solutions varied $(2.5 \mathrm{mg} / \mathrm{ml}, 5.0 \mathrm{mg} / \mathrm{ml}, 7.5 \mathrm{mg} / \mathrm{ml})$ depending on the $\mathrm{KCN}$ dose administered. After adjusting the starting dose and the stage-distance (dose difference between stages) for each group, the software (described above) provided information on the dose for the next stage. Based on the slopes of the log dose-response curves 
determined in earlier cyanide studies (Petrikovics et al., 1994) by the classic LitchfieldWilcoxon method (Litchfield and Wilcoxon, 1949), the log dose difference was set as 0.1 for all groups in the program. After injection, based on the result of the observation, (alive or dead), the next stage was determined by the software: If the animal died, the next stage had lower KCN dose, if the animal survived, the next stage had higher KCN dose.

When the stopping condition has been met, the program determined the $L_{50}$ values with $95 \%$ confidence limits. In the up-and-down method 10-18 mice were used for each $\mathrm{LD}_{50}$ determination. In each group, the number of stages/animals depended on how close the starting dose was to the expected LD $_{50}$ value (Bruce, 1985; Efron, 1979). The APR values were expressed as the ratio of the $L D_{50}$ estimate of $K C N$ with the antagonist(s) and the $\mathrm{LD}_{50}$ estimate of $\mathrm{KCN}$ without antidote (control).

\section{Statistical Analysis}

The APR values of the treatment groups in figures were compared by applying statistical analysis with GraphPad Prism 5.0 (GraphPad Software Inc., San Diego, California). In case of testing the effect of neat vs. Poly80 formulated DMTS and the effect of $25 \mathrm{vs}$. $50 \mathrm{mg} / \mathrm{kg}$ bodyweight doses of DMTS two-way ANOVA was used with Bonferroni posttest. For evaluating the effect of different combinations of DMTS and 4NCbi or AHCbi separated treatment groups were compared with Student t-test or oneway ANOVA followed by Dunnett's Multiple Comparison Test. Each comparison is specified in the description of figures. Changes were considered statistically significant at $p<0.01$. 
With the Dixon up-and-down method, the $\mathrm{LD}_{50}$ doses with the estimated $95 \%$ confidence intervals $(\mathrm{Cl})$ for DMTS were calculated using software algorithms described in "Implementation of Dixon \& Massey UDP," Introduction to Statistical Analysis, 1983, pp 434-438.

\section{Results}

CN antidotal protection of DMTS alone (neat and Poly80 formulated) and in combinations with two Cbi derivatives (4NCbi and $\mathrm{AHCbi}$ ) are presented. The antidotal efficacy was expressed as APR, where APR is the ratio of $L D_{50}$ of $C N$ in the presence of the antidote and the $\mathrm{LD}_{50}$ of $\mathrm{CN}$ without the antidote (control).

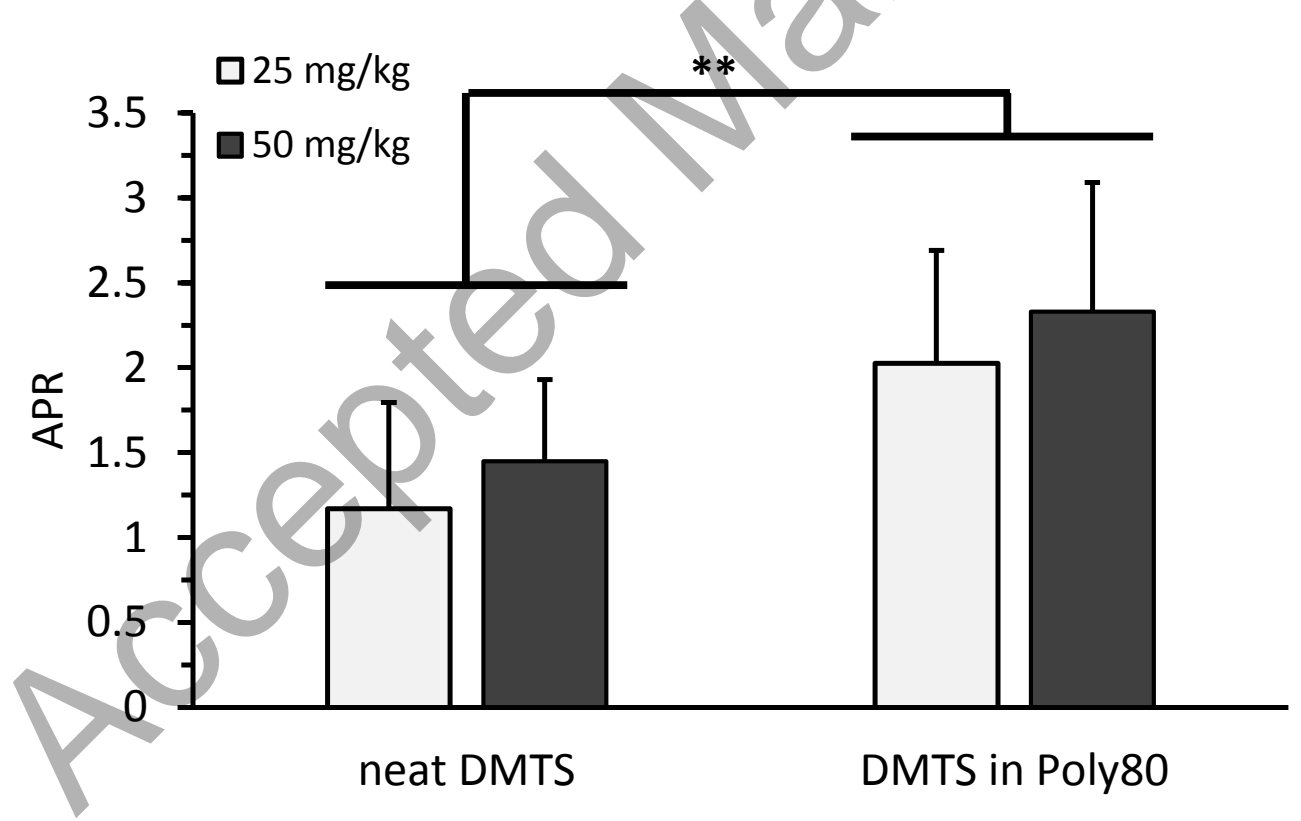

Figure 1. The antidotal effect (APR) of neat DMTS vs. DMTS-Poly80 against CN intoxication in mice. The $A P R$ values are presented as means $\pm S D(n=5-13)$. Statistical analysis: Two-way ANOVA followed by Bonferroni posttest. Statistically 
significant differences ( $\left.{ }^{* *}, P<0.01\right)$ were detected between the neat DMTS and Poly80DMTS at 25 and $50 \mathrm{mg} / \mathrm{kg}$ bodyweight doses.

The mean $L D_{50}$ of the related control (KCN alone treatment) for the experiments with neat DMTS was 7.79 (95\% Cl was 5.66-10.72). The mean $L D_{50}$ of related control (KCN alone treatment) for the experiments with DMTS-Poly80 was 6.78 (95\% Cl was 5.418.49).

Figure 1. shows the APR values of neat DMTS vs. the DMTS-Poly80 at DMTS doses of 25 and $50 \mathrm{mg} / \mathrm{kg}$ bodyweight. Without the Poly80-formulation, the neat DMTS showed unremarkable protection at the investigated doses, however, the APR values of 1.17 (dose: $25 \mathrm{mg} / \mathrm{kg}$ bodyweight) and 1.45 (dose: $50 \mathrm{mg} / \mathrm{kg}$ bodyweight) of the neat DMTS were significantly enhanced $(p=0.0024)$ by the Poly 80 formulation. The enhanced APR values for the Poly80-DMTS were 2.03 and 2.33 at the doses of 25 and $50 \mathrm{mg} / \mathrm{kg}$ bodyweight, respectively.

. In order to enhance the antidotal efficacy, and reducing the side effects, combinations of DMTS-Poly80 with Cbi derivatives were explored. 
Table 1. Cyanide $L D_{50}$ values and $C N$ antidotal protections with DMTS-Poly80 + $4 \mathrm{NCbi}$ combinations.

\begin{tabular}{|c|c|c|c|c|}
\hline $\begin{array}{l}\text { Experi- } \\
\text { ments }\end{array}$ & Treatment $^{a}$ & $n^{b}$ & $\begin{array}{c}\mathrm{LD}_{50}(\mathrm{mg} \mathrm{KCN} / \mathrm{kg}) \\
(95 \% \mathrm{Cl}){ }^{c}\end{array}$ & $\begin{array}{l}\mathrm{APR}(\text { mean) } \pm \mathrm{SD} \\
\text { (related control) }^{d}\end{array}$ \\
\hline $1-1$ & $\begin{array}{l}\text { KCN alone } \\
\text { (Control } \mathrm{A})\end{array}$ & 12 & $\begin{array}{c}6.17 \\
(4.94-7.75)\end{array}$ & $1.00 \pm 0.40$ \\
\hline $1-2$ & $\begin{array}{l}\mathrm{KCN} \text { alone } \\
\text { (Control B) }\end{array}$ & 8 & $\begin{array}{c}6.78 \\
(5.41-8.49) \\
\end{array}$ & $1.00 \pm 0.33$ \\
\hline $1-3$ & $\begin{array}{l}\text { KCN alone } \\
\text { (Control C) }\end{array}$ & 15 & $\begin{array}{c}8.91 \\
(7.55-10.50)\end{array}$ & $1.00 \pm 0.33$ \\
\hline $1-4$ & $\begin{array}{c}\mathrm{KCN}+ \\
\text { 4NCbi }(20 \mathrm{mg} / \mathrm{kg})\end{array}$ & 9 & $\begin{array}{c}8.32 \\
(6.25-11.06)\end{array}$ & $\begin{array}{l}1.35 \pm 0.60 \\
(\text { Control A) }\end{array}$ \\
\hline $1-5$ & $\mathrm{KCN}+\mathrm{DMTS}(25 \mathrm{mg} / \mathrm{kg})$ & 9 & $\begin{array}{c}13.73 \\
(11.10-16.99)\end{array}$ & $\begin{array}{l}2.03 \pm 0.67 \\
(\text { Control B) }\end{array}$ \\
\hline $1-6$ & $\mathrm{KCN}+\mathrm{DMTS}(50 \mathrm{mg} / \mathrm{kg})$ & 13 & $\begin{array}{c}15.78 \\
(13.22-18.84)\end{array}$ & $\begin{array}{l}2.33 \pm 0.76 \\
\text { (Control B) }\end{array}$ \\
\hline $1-7$ & $\begin{array}{c}\mathrm{KCN}+4 \mathrm{NCbi}(20 \mathrm{mg} / \mathrm{kg})+ \\
\text { DMTS }(25 \mathrm{mg} / \mathrm{kg})\end{array}$ & 9 & $\begin{array}{c}21.20 \\
(17.14-26.23)\end{array}$ & $\begin{array}{l}2.38 \pm 0.78 \\
\text { (Control C) }\end{array}$ \\
\hline $1-8$ & $\begin{array}{c}\mathrm{KCN}+4 \mathrm{NCbi}(20 \mathrm{mg} / \mathrm{kg})+ \\
\text { DMTS }(50 \mathrm{mg} / \mathrm{kg})\end{array}$ & 10 & $\begin{array}{c}27.75 \\
(22.43-34.33)\end{array}$ & $\begin{array}{l}3.12 \pm 1.08 \\
(\text { Control C) }\end{array}$ \\
\hline
\end{tabular}

${ }^{a}$ The aqueous KCN solutions were injected subcutaneously, and the antidotes were injected intramuscularly. The injection solution of $50 \mathrm{mg} / \mathrm{ml}$ DMTS in Poly80 was used for the DMTS-Poly80 administrations. The injection solution of $40 \mathrm{mg} / \mathrm{ml} 4 \mathrm{NCbi}$ in Poly80 was used for the 4NCbi administrations. When DMTS-Poly80 and 4NCbi were administered in combination, they were injected into separate legs. The injection volume was calculated based on the stock solution concentration, the dose, and the weight of the animals.

${ }^{b} n$ represents the number of animals used in each experiments.

${ }^{c}$ The $L D_{50}$ values were determined by the up-and-down method (Dixon, 1965) and expressed as mean $+/-95 \%$ confidence limits.

${ }^{d}$ The $A P R$ values were calculated as $L D_{50}$ of $C N$ with the antidotes $/ L D_{50}$ of $C N$ without antidote (control). For each experimental setup, a control group was included. 


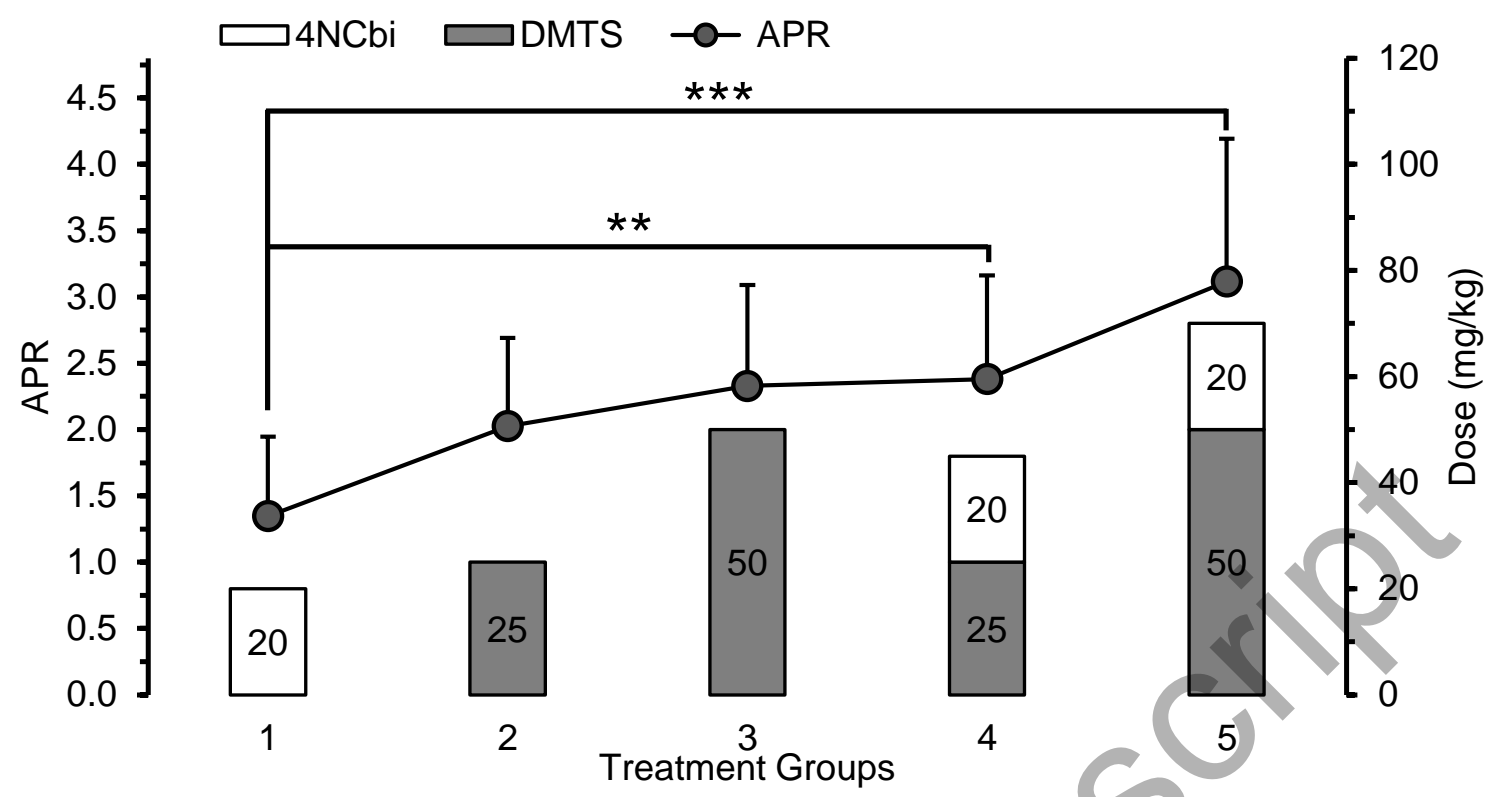

Figure 2. Cyanide antidotal protections (APR) with DMTS-Poly80 alone and in combinations with $4 \mathrm{NCbi}$ when the $4 \mathrm{NCbi}$ dose was constant and the DMTS doses varied. Groups: 1 - 4NCbi (20 mg/kg); 2 - DMTS (25 mg/kg); 3 - DMTS (50 mg/kg); 4 [DMTS (25 mg/kg) + 4NCbi (20 mg/kg)]; 5- [DMTS (50 mg/kg) + 4NCbi $(20 \mathrm{mg} / \mathrm{kg})]$. $A P R$ values are presented as means $\pm S D(n=8-15)$. Statistical analysis: ANOVA followed by Dunnet's Multiple Comparison Test. Statistical significance calculations were performed between Group 4 vs. Group 1 and Group 2; Group 5 vs. Group 1 and Group 3. Significant difference was detected when Group 4 was compared to Group 1 $\left.{ }^{* *}, P<0.01\right)$, and when Group 5 was compared to Group $\left.1{ }^{* * *}, P<0.001\right)$.

Figure 2. (from Table 1. data) shows the APR values for DMTS-Poly80 used in combination with $4 \mathrm{NCbi}$. The $4 \mathrm{NCbi}$ dose was constant $(20 \mathrm{mg} / \mathrm{kg})$, and the dose of DMTS in $15 \%$ Poly 80 varied $(25 \mathrm{mg} / \mathrm{kg}$ and $50 \mathrm{mg} / \mathrm{kg}$ ). Each time, the antidotes were injected IM one minute after $\mathrm{CN}$ injection. For the statistical comparison, the antidotal effect (APR) of DMTS-Poly80 and $4 \mathrm{NCbi}$ combinations were compared to the 
corresponding doses of the compounds alone. DMTS-Poly80 in the doses of 25 and 50 $\mathrm{mg} / \mathrm{kg}$ significantly $(\mathrm{p}<0.01)$ elevated the antidotal effect of $4 \mathrm{NCbi}$ in $20 \mathrm{mg} / \mathrm{kg}$ dose (Group 4 vs. Group 1; or Group 5 vs. Group 1). The presence of 4NCbi (20 mg/kg) enhanced the antidotal protection of DMTS-Poly80 alone at the investigated doses of 25 and $50 \mathrm{mg} / \mathrm{kg}$ (Group 5 vs. Group 3; or Group 4 vs. Group 2), however this increase was not significant.

Table 2. Cyanide $L D_{50}$ values and $C N$ antidotal protections with DMTS-Poly80 + AHCbi combinations.

\begin{tabular}{|c|c|c|c|c|}
\hline $\begin{array}{l}\text { Experi- } \\
\text { ments }\end{array}$ & Treatment $^{a}$ & $\mathrm{n}^{b}$ & $\begin{array}{c}\mathrm{LD}_{50}(\mathrm{mg} \mathrm{KCN} / \mathrm{kg} \\
(95 \% \mathrm{Cl})^{\mathrm{c}}\end{array}$ & $\begin{array}{l}\mathrm{PR}(\text { mean }) \pm \mathrm{SD} \\
\text { elated control) }\end{array}$ \\
\hline $2-1$ & $\begin{array}{l}\mathrm{KCN} \text { alone } \\
\text { (Control D) }\end{array}$ & 7 & $\begin{array}{c}10.94 \\
(8.59-13.91)\end{array}$ & $1.00 \pm 0.33$ \\
\hline $2-2$ & $\begin{array}{l}\mathrm{KCN} \text { alone } \\
\text { (Control E) }\end{array}$ & 8 & $\begin{array}{c}9.84 \\
(7.85-12.33)\end{array}$ & $1.00 \pm 0.33$ \\
\hline $2-3$ & $\begin{array}{l}\text { KCN alone } \\
\text { (Control F) }\end{array}$ & 6 & $\begin{array}{c}11.40 \\
(8.79-14.80)\end{array}$ & $1.00 \pm 0.33$ \\
\hline $2-4$ & $\begin{array}{c}\mathrm{KCN}+ \\
\text { AHCbi }(250 \mathrm{mg} / \mathrm{kg})\end{array}$ & & $\begin{array}{c}23.12 \\
(18.69-28.61) \\
\end{array}$ & $\begin{array}{l}2.35 \pm 0.77 \\
\text { (Control E) }\end{array}$ \\
\hline $2-5$ & $\begin{array}{c}\text { KCN + } \\
\text { DMTS }(100 \mathrm{mg} / \mathrm{kg})\end{array}$ & & $\begin{array}{c}36.00 \\
(28.73-45.12) \\
\end{array}$ & $\begin{array}{l}3.29 \pm 1.08 \\
\text { (Control D) }\end{array}$ \\
\hline $2-6$ & $\begin{array}{c}\mathrm{KCN}+ \\
\text { DMTS }(100 \mathrm{mg} / \mathrm{kg})+ \\
\text { AHCbi }(50 \mathrm{mg} / \mathrm{kg})\end{array}$ & 9 & $\begin{array}{c}41.34 \\
(33.42-51.14)\end{array}$ & $\begin{array}{l}3.63 \pm 1.19 \\
\text { (Control F) }\end{array}$ \\
\hline $2-7$ & $\begin{array}{c}\mathrm{KCN}+ \\
\text { DMTS }(100 \mathrm{mg} / \mathrm{kg})+ \\
\text { AHCbi }(100 \mathrm{mg} / \mathrm{kg})\end{array}$ & 7 & $\begin{array}{c}47.40 \\
(36.53-61.51)\end{array}$ & $\begin{array}{l}4.16 \pm 1.48 \\
\text { (Control F) }\end{array}$ \\
\hline & $\begin{array}{c}\mathrm{KCN}+ \\
\text { DMTS }(100 \mathrm{mg} / \mathrm{kg})+ \\
\text { AHCbi }(250 \mathrm{mg} / \mathrm{kg})\end{array}$ & 9 & $\begin{array}{c}57.66 \\
(46.01-72.25)\end{array}$ & $\begin{array}{l}5.86 \pm 2.04 \\
\text { (Control E) }\end{array}$ \\
\hline
\end{tabular}

${ }^{a}$ The aqueous KCN solutions were injected subcutaneously, and the antidotes were injected intramuscularly. The stock solution of $50 \mathrm{mg}$ DMTS/mI Poly80 was used for the DMTS-Poly80 administrations. The stock solution of $125 \mathrm{mg} \mathrm{AHCbi} / \mathrm{ml}$ water was used for the AHCbi administrations. When DMTS and AHCbi were administered in combination, 
they were injected into separate legs. The injection volume was calculated based on the stock solution concentration, the dose, and the weight of the animals.

${ }^{b} n$ represents the number of animals used in each experiments.

${ }^{c}$ The $L D_{50}$ values were determined by the up-and-down method (Dixon, 1965) and expressed as mean $+/-95 \%$ confidence limits.

${ }^{d}$ The APR values were calculated as $L D_{50}$ of $C N$ with the antidotes $/ L D_{50}$ of $C N$ without antidote (control). For each experimental setup, a control group was included.

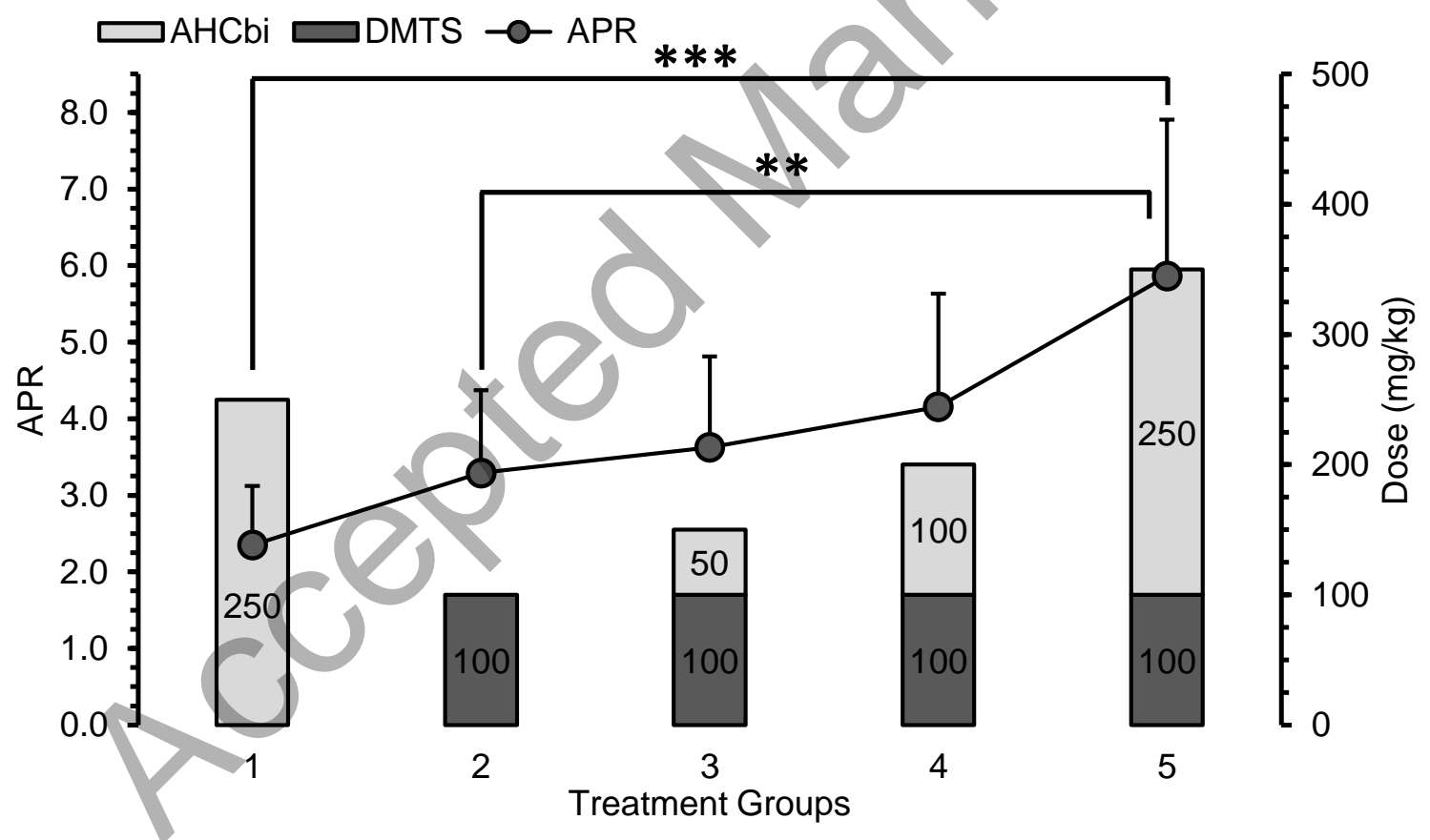

Figure 3. Cyanide antidotal protections (APR) with DMTS-Poly80 alone and in combinations with AHCbi when the DMTS dose was constant, and the AHCbi doses varied. Groups: 1 - AHCbi (250 mg/kg); 2 - DMTS (100 mg/kg); 3 - [DMTS (100 mg/kg) + AHCbi (50 mg/kg)]; 4 - [DMTS (100 mg/kg) + AHCbi (100 mg/kg)]; 5 - [DMTS (100 
$\mathrm{mg} / \mathrm{kg})+$ AHCbi $(250 \mathrm{mg} / \mathrm{kg})]$. APR values are presented as means $\pm S D(n=7-9)$. Statistical significance calculations were performed between Group 2 vs. Group 3, Group 4, and Group 5 by ANOVA complemented with Dunnett's Multiple Comparison Test. Student t-test were applied to check the significant differences between Group 5 vs. Group 1. Statistically significant difference was detected when Group 5 was compared to Group $\left.1{ }^{* * *}, P<0.001\right)$ and Group $2\left({ }^{* *}, P<0.01\right)$.

Figure 3. (from Table 2. data), shows the APR values for the combinations of AHCbi + DMTS-Poly80 when the DMTS dose was constant $(100 \mathrm{mg} / \mathrm{kg})$ and the doses of AHCbi varied $(50,100$ and $250 \mathrm{mg} / \mathrm{kg}$ ). For statistical calculations the effect of DMTS and AHCbi combinations were compared to the effect of DMTS alone. AHCbi at the doses of 50 or $100 \mathrm{mg} / \mathrm{kg}$ did not significantly improve the antidotal effect of DMTS at the dose of $100 \mathrm{mg} / \mathrm{kg}$ (Group 3 vs. 2 or Group 4 vs. 2). However, AHCbi at the dose of $250 \mathrm{mg} / \mathrm{kg}$ statistically significantly $(p<0.01)$ enhanced the APR of DMTS (Group 2 vs. Group 5), and the DMTS $(100 \mathrm{mg} / \mathrm{kg})$ also significantly $(p<0.001)$ enhanced the effect of AHCbi (250 mg/kg), (Group 1 vs. Group5).

\section{Discussion and Conclusions}

This study focused on A) antidotal protection with neat DMTS vs. Poly80 formulated DMTS; B) antidotal protections with DMTS-Poly80 alone vs. in combinations with Cbi derivatives (4NCbi or $\mathrm{AHCbi})$.

To enhance the absorption of the antidote DMTS to the blood and as a consequence, to improve its antidotal effect and bioavailability, a well-designed, technological formulation 
should be applied. The DMTS-Poly80 formulation with the use of the excipient Poly80, commonly used for drug formulation in pharmaceutical technology was intensively investigated and the results were published earlier (Kiss et al., 2017; Kovacs et al., 2016a; Rockwood et al., 2016). This formulation provided the advantages of good absorption kinetics and high antidotal efficacy. Our studies confirmed that the Poly80 formulation not only significantly enhanced the APR of the neat DMTS, but it also nearly eliminated (minimized) the tissue damage caused by the injection of DMTS without Poly80 (Petrikovics, unpublished data). While the APR values with the neat DMTS at the doses of 25 and $50 \mathrm{mg} / \mathrm{kg}$ bodyweight, and with the Poly 80 formulated DMTS at the dose of $25 \mathrm{mg} / \mathrm{kg}$ bodyweight have never been published, the APR value for DMTS alone at the dose of $50 \mathrm{mg} / \mathrm{kg}$ bodyweight DMTS (Kovacs et al., 2016a) is shown here only for comparison. Another alternative way to enhance the antidotal effect is the application of antidotal drug combinations, which can take advantage of multiple mechanisms of action.

Here we report APRs obtained with DMTS in combinations with $4 \mathrm{NCbi}$ and AHCbi (Figures 2. and 3; Tables 1. and 2.). The $4 \mathrm{NCbi}(20 \mathrm{mg} / \mathrm{kg}$ bodyweight) provided an APR of 1.35 alone. The AHCbi alone showed remarkable antidotal effects (APR of 2.35) only at a higher dose $(250 \mathrm{mg} / \mathrm{kg}$ bodyweight). For both combinations ([DMTS $+4 \mathrm{NCbi}]$ and [DMTS + AHCbi]) the APR values were higher than for any of the components alone, and in some cases the increase in the APR-values were significant.

The mechanism of action for each component are different: the major mechanism of DMTS is attributed to its sulfur donor effect, when it reacts with $\mathrm{CN}$ and converts it to the less toxic thiocyanate (Schulz, 1984; Way et al., 1988). However, unlike thiosulfate, the 
sulfur donor component of the present $\mathrm{CN}$ antidote therapy of Nithiodote ${ }^{\mathrm{TM}}$, DMTS can convert $\mathrm{CN}$ to thiocyanate effectively, even without the sulfurtransferase enzyme, Rhodanese, but definitely less effectively than in the presence of Rhodanese. Recently it has been reported that DMTS can oxidize hemoglobin to MetHb (Dong et al., 2017). Since MetHb has high affinity to $\mathrm{CN}$, MetHb can act as a scavenger (Pearce et al., 2003; Way et al., 1988). This feature of DMTS can be considered as a minor mechanism for $\mathrm{CN}$ antidotal action. Despite the fact that nitrite, the other component of Nithiodote $^{T M}$, is a long known and well investigated MetHb former, its capability to form nitric oxide recently became the focus of investigations (Kanai et al., 2001). Nitric oxide modulates the binding of $\mathrm{CN}$ to Cyt $\mathrm{c}$ Oxidase. On the other hand, the $4 \mathrm{NCbi}, \mathrm{a}$ combination of 1 eqv. DNCbi +2 eqv. of nitrite, may also act as a MetHb former, and the Cbi by itself is a scavenger type $\mathrm{CN}$ antidote (Chen, 1952).

Our combination studies proved that the $\mathrm{CN}$ antidotal effects of DMTS can be enhanced by combining it with Cbi derivatives in a dose dependent manner. The AHCbi showed significant enhancement on the antidotal effect of DMTS at a higher, $(250 \mathrm{mg} / \mathrm{kg}$ bodyweight) dose only, while the dose of $4 \mathrm{NCbi}(20 \mathrm{mg} / \mathrm{kg}$ bodyweight) was too low to achieve a significant enhancement on the antidotal effect of DMTS. However, from the side of DMTS, it significantly enhanced the APR for both $4 \mathrm{NCbi}$ and AHCbi at all investigated doses.

Although the $15 \%$ Poly 80 formulation is considered successful (Kovacs et al., 2016a), there are ongoing studies in our lab and our collaborating labs to develop more advanced formulations. These can further enhance the solubility, the bioavailability and the antidotal efficacy with lower DMTS doses, when applied alone. Since the solubility 
of DMTS in the $15 \%$ Poly 80 is not high enough to maintain suitable injection volumes for humans, investigations are focusing on advanced technological formulations with higher DMTS solubility.

\section{Conflict of interest statement}

The authors declare no conflicts of interest associated with this study.

\section{Disclosure}

Two patents by two coauthors, related to DMTS are: 1.) Gary A. Rockwood, Ilona Petrikovics (SHSU) and Steven I. Baskin (USAMRICD): Dimethyl Trisulfide as a Cyanide Antidote. U.S. Patent No. 9,375,407, 2016, 2.) Ilona Petrikovics and Kristóf Kovács (SHSU). Formulations of Dimethyl Trisulfide for Use as a Cyanide Antidote. U.S. Patent No. 9,456,996, 2016.

\section{Acknowledgements}

The authors are thankful for Ms. Ashley C. Whiteman, Ms. Anna Duke and Mr. Stephen Lee, for technical assistance. Special thanks to Dr. David Thompson for scientific discussions.

\section{Funding}

This research was supported by the CounterACT Program, National Institutes of Health

Office of the Director, and the National Institute of Allergy and Infectious Diseases, $\mathrm{NIH}$ / Department of Defence Interagency Agreement [AOD14020-001-00000/A120-B.P2014- 
01], and the Robert A. Welch Foundation [X-0011] at Sam Houston State University, Huntsville, TX.

\section{References}

Block, E. 1985. The chemistry of garlic and onions. Sci Am. 252, 94-9.

Borron, S. W., Stonebrook, M., Reid, F. 2006. Efficacy of hydroxocobalamin for treatment of acute cyanide poisoning in adult beagle dogs. Clin Toxicol. 44, 5-15.

Broderick, K. E., Singh, V., Zhuang, S., Kambo, A., Chen, J. C., Sharma, V. S., Pilz, R. B., Gerry R. Boss, G. R., 2005. Nitric oxide scavenging by the cobalamin precursor cobinamide. J Biol Chem. 280, 8678-85.

Bruce, R. D. 1985. An up-and-down procedure for acute toxicity testing. Fundam Appl Toxicol. 5, 151-7.

Chan, A., Balasubramanian, M., Blackledge, W., Mohammad, O. M., Alvarez, L., Boss, G. R., Bigby, T. D. 2018. Cobinamide is superior to other treatments in a mouse model of cyanide poisoning. Clin Toxicol. 48, 709-17.

Chan, A., Jiang, J., Fridman, A., Guo, L. T., Shelton, G. D., Liuy, M. T., Green, C., Haushalter, K. J., Patel, H. H., Lee, J., Yoon, D., Burney, T., Mukai, D., Mahon, S. B., Brenner, M., Pilz, R. B., Boss, G. R. 2015. Nitrocobinamide, a new cyanide antidote that can be administered by intramuscular injection. J Med Chem. 58, 1750-9.

Chen, K. K. 1952. Nitrite and thiosulfate therapy in cyanide poisoning. J Amer Med Assoc. 149, 113-9.

Cronican, A. A., Frawley, K. L., Straw, E. P., Lopez-Manzano, E., Praekunatham, H., Peterson, J., Pearce, L. L. 2018. A comparison of the cyanide-scavenging capabilities of some cobalt-containing complexes in mice. Chem Res Toxicol. 31, 259-68.

DeLeon, S. M., Downey, J. D., Hildenberger, D. M., Rhoomes, M. O., Booker, L., Rockwood, G. A., Basi, K. A. 2018. DMTS is an effective treatment in both inhalation and injection models for cyanide poisoning using unanesthetized mice. Clin Toxicol. 56, 332-41.

De Silva, D., Lee, S., Duke, A., Angalakurthi, S., Chou, C. E., Ebrahimpour, A., Thompson, D. E., Petrikovics, I. 2016. Intravascular residence time determination for the cyanide antidote dimethyl trisulfide in rat by using liquid-liquid extraction coupled with high performance liquid chromatography. J Anal Methods Chem. 6546475, 1-6.

Dixon, W. J. 1965. The up-and-down method for small animal samples. J Amer Stat Assoc. 60, 967-78.

Dixon WJ, Massey FJ. 1983. Introduction to Statistical Analysis. [Frederick (MD)] McGraw-Hill Inc. "p. 434-438" ISBN-10: 0070170738.

Dong, X., Kiss, L., Petrikovics, I., Thompson, D.E. 2017. Reaction of dimethyl trisulfide with hemoglobin. Chem Res Toxicol. 30, 1661-3. 
Efron, B. 1979. Bootstrap methods: another look at the jackknife. Ann Statist. 7, 1-26. Kanai, A. J., Pearce, L. L., Clemens, P. R., Birder, L. A., Van Bidder, M. M., Choi, S. Y., de Groat, W. C., Peterson, J. 2001. Identification of a neuronal nitric oxide synthase in isolated cardiac mitochondria using electrochemical detection. Proc Natl Acad Sci USA. 98, 14126-31.

Kiss, L., Bocsik, A., Walter, F. R., Ross, J., Brown, D., Mendenhall, B. A., Crews, S. R., Lowry, J., Coronado, V., Thompson, D. E., Sipos, P., Szabó-Révész, P., Deli, M. A., Petrikovics, I. 2017. In vitro and in vivo blood-brain barrier penetration studies with the novel cyanide antidote candidate dimethyl trisulfide in mice. Toxicol Sci. 160, 398-407.

Kovacs, K., Duke, A. C., Shifflet, M., Winner, B., Lee, S. A., Rockwood, G. A., Petrikovics, I. 2016a. Parenteral dosage form development and testing of dimethyl trisulfide, as an antidote candidate to combat cyanide intoxication. Pharm Dev Technol. 7450, 1-6.

Kovacs, K., Jayanna, P. K., Duke, A., Winner, B., Negrito, M., Angalakurthi, S., Yu, J. C., Füredi, P., Ludányi, K., Sipos, P., Rockwood, G. A., Petrikovics, 1. 2016b. A lipid base formulation for intramuscular administration of a novel sulfur donor for cyanide antagonism. Curr Drug Deliv. 13, 1351-7.

Lee, J., Mahon, S. B., Mukai, D., Burney, T., Katebian, B. S., Chan, A., Bebarta, V. S., Yoon, D., Boss, G., Brenner, M. 2016. The vitamin B12 analog cobinamide is an effective antidote for oral cyanide poisoning. J Med Toxicol. 12, 370-9.

Litchfield, J. T., Wilcoxon, F. 1949. A simplified method of evaluating dose-effect experiments. J Pharmacol Exp Ther. 96, 99-113.

Marraffa, J. M., Cohen, V., Howland, M. A. 2012. Antidotes for toxicological emergencies. Am J Health Syst Pharm. 69, 199-212.

Pearce, L. L., Bominaar, E. L., Hill, B. C., Peterson, J. 2003. Reversal of cyanide inhibition of cytochrome c oxidase by the auxiliary substrate nitric oxide: an endogenous antidote to cyanide poisoning. J Biol Chem. 278, 52139-45.

Petrikovics, I., McGuinn, W.D., Cannon, E.P., Pei, L., Way, J.L. 1994. Encapsulation of rhodanese and organic thiosulfonates by mouse erythrocytes. Fundam and Appl Toxicol. 23, 70-75.

Rockwood, G. A., Thompson, D. E., Petrikovics, I. 2016. Dimethyl trisulfide: A novel cyanide countermeasure. Toxicol Ind Health. 32, 2009-16.

Schulz, V. 1984. Clinical pharmacokinetics of nitroprusside, cyanide, thiosulphate and thiocyanate. Clin Pharmacokinet. 9, 239-51.

Scottsdale, A. Z. 2011. Nithiodote. Sodium nitrate injection and sodium thiosulfate injection Package Insert: Hope Pharmaceuticals.

Vogel, S. N., Sultan, T. R., Ten Eyck, R. P. 1981. Cyanide poisoning. Clin Toxicol. 18, 367-83. 
Way, J. L., Leung, P., Cannon, E., Morgan, R., Tamulinas, C., Leong-Way, J., Baxter, L., Nagi, A., Chui, C. 1988. The mechanism of cyanide intoxication and its antagonism. Ciba Found Symposium. 140, 232-43.

Zakharov, S., Vaneckova, M., Seidl, Z., Diblik, P., Kuthan, P., Urban, P., Navratil, T., Pelclova, D. 2015. Successful use of hydroxocobalamin and sodium thiosulfate in acute cyanide poisoning: a case report with follow-up. Basic Clin Pharmacol Toxicol. 117, 209-12. 